\title{
Determining parameters of electric power unit for light aircraft
}

\author{
Bakholdin Dmitry \\ Department of Electrotechnical Complex \\ NSTU \\ Novosibirsk, Russia \\ baholdin@ngs.ru
}

\author{
Biryukov Valery \\ Department of Electrotechnical Complex \\ NSTU \\ Novosibirsk, Russia \\ vavib49@mail.ru
}

\author{
Tolstobrova Lyudmila \\ Foreign Languages Department \\ NSTU \\ Novosibirsk, Russia \\ tolstobrova@corp.nstu.ru
}

\begin{abstract}
The article is devoted to the comparison of the characteristics of electric traction aircrafts and those equipped with classic ICE. The calculation of the flight range of aircraft equipped with an electric motion has been made.
\end{abstract}

Keywords-electric power unit; light aircraft; flight range;

\section{INTRODUCTION}

In recent years the aircraft industry has been increasingly interested in an electric motor application as the main power unit. This trend is explained by the production of advanced engineering structural materials, the reduction in the cost of high power permanent magnets, the development of the element base and, most importantly, the steady improvement of the characteristics of electric energy storage system.

To assess the prospects of using a permanent magnet electric motor instead of the traditional gasoline engine for small aircraft, it is necessary to carry out comparative analysis of power unit's data.

- Indicators of specific capacity for modern electric motors have close values of $8-10 \mathrm{~kW} / \mathrm{kg}$ which corresponds to gas turbine units - the best among ICE in this parameter and much higher than for piston engines - 2-3 kW / kg. At the same time, the energy intensity of the sources differs in favor of hydrocarbon fuels so the field of electric motor application is limited to a small aircraft. Such engines are applicable at the required power for the power unit up to $500-700 \mathrm{~kW}$ and are able to replace gasoline analogues [1].

- One of the most important and indisputable advantages of the electric motor is the absence of harmful emissions and hence the ecological cleanness of transport equipped with electric motor.
- The cost of a modern aircraft engine is much higher/expensive than an electric motor of comparable power including its operation.

- In contrast to the engine, the electric motor power does not depend on the flight altitude and the engine torque speed range is almost constant that in some cases allows us to abandon the use of the gearbox.

- The piston engine is poorly balanced in terms of vibration, which adversely affects comfort, reliability and fatigue life of the entire aircraft, and it also has a much lower resource and fail-operational capability due to much more details [2].

- Modern photovoltaic technologies have advanced significantly in its development and allow the use of photocells on the outer skin of the wing and fuselage without reducing their aerodynamic performance and providing the aircraft with additional energy directly during the flight.

- The electricity price is much lower than for various types of aviation fuel. The efficiency of the modern internal combustion engine varies within the limits of $22-30 \%$ and reaches maximum in a narrow speed range for the electric motor efficiency values of 88$96 \%$ is nominal for most operating modes.

- Aviation fuel and lubricants are highly fire dangerous in case of fuel spill. Fire in an airplane is one of the worst accidents. The causes of the fire can be very different, but if there is no fuel in the resin, the probability of a fire will decrease significantly. 


\section{THEORY}

Calculations were carried out by the example of several existing aircrafts in order to compare the flight characteristics of the aircraft with different types of engines [2]. The calculation was carried out based on the assumption of the aircraft weight with different types of the engine. For this purpose the gasoline power unit weight and the fuel system were determined from the flight operation manual. This assumption allows us to preserve the initial aerodynamic, strength and performance characteristics of the aircraft.

The layouts of the elements of the power units are shown in Figures 1 and 2 [3]

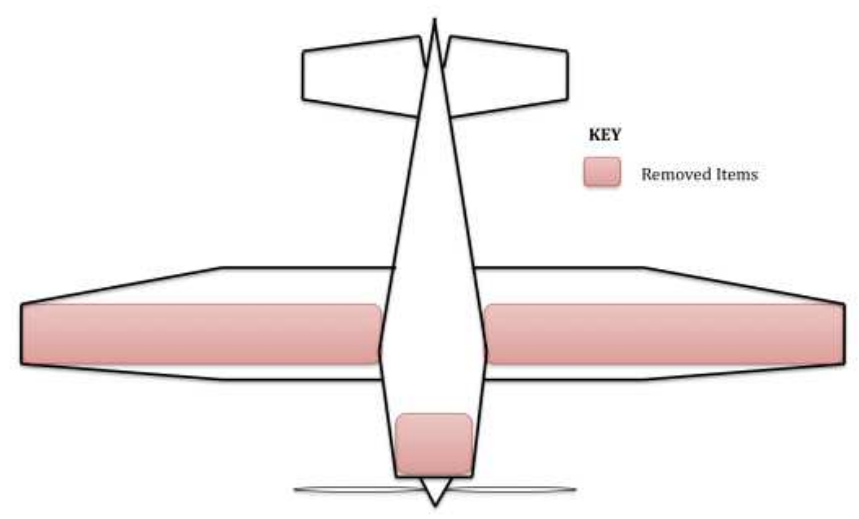

Fig. 1. Empty Weight

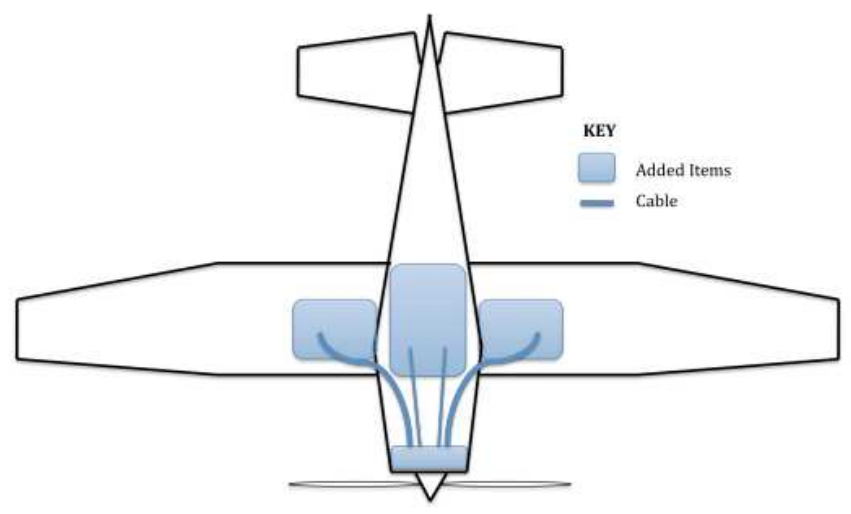

Fig. 2. Electrical Solution

To calculate the aircraft energy parameters [4], the entire flight process can be divided into parts:

- Taking-off

- Climbing

- Level flight

- Push down

- Landing

It is assumed that using power unit based on an electric motor and energy will be consumed only in the first three stages each of which is considered separately, the characteristic points and flight modes are shown in Figure 3.
The assumption is based on the choked gasoline engine in these modes.

In a take-off and climb mode, the maximum possible engine thrust of the power unit is used in the long-term mode, while it remains possible to briefly use the permissible overload of the engine to reduce the take-off distance or more intensive climb [5]. At cruise flight to ensure maximum range, it is necessary to use the flight mode corresponding to the most efficient power consumption and the maximum possible aerodynamic efficiency - an indicator characterizing the ratio of the lift-drag polar.

As a result of calculating the flight characteristics, the required power, speed range, climb rate, distance and take-off and landing speeds are determined [6], [7], [8]. An approximate quantitative evaluation of these indicators requires the following initial data:

- Geometric parameters and aircraft weight.

- Power engine and the dependence of the thrust and propeller efficiency on speed.

- Aerodynamic characteristics: the dependence of the powered lift coefficient $C_{y a}$ on the angle of attack and the polar $C_{x a}=f\left(C_{y a}\right)$.

\section{Required power for level flight.}

The required power for established level flight is given by formula:

$$
N_{r e q}=\frac{G \cdot V}{270 K}
$$

where $G$ - plane weight, $\mathrm{kg}$;

$$
\begin{aligned}
& K=\frac{C_{x a}}{C_{y a}}-\text { aerodynamic efficiency: } \\
& \qquad C_{y a} \cong 207 \frac{G}{S} \cdot \frac{1}{V^{2}}
\end{aligned}
$$

The polar that is the dependence $C_{x a}=f\left(C_{y a}\right)$ in the flight range of angles of attack can be approximated by the equation of quadratic parabola: parabolic drag polar:

$$
C_{x a}=C_{x_{\min }}+A\left(C_{y a}-B\right)
$$

where $C_{x_{\min }}$ is the minimum coefficient of resistance;

$A$ - drag-due-to-lift coefficient, induced component of the resistance;

$B$ - the "lifting" polar coefficient is numerically equal to $C_{y a}$ at which the minimum aerodynamic resistance is achieved. $B \neq 0$ only for wings with reclined configuration or having thin profile with large curvature. 


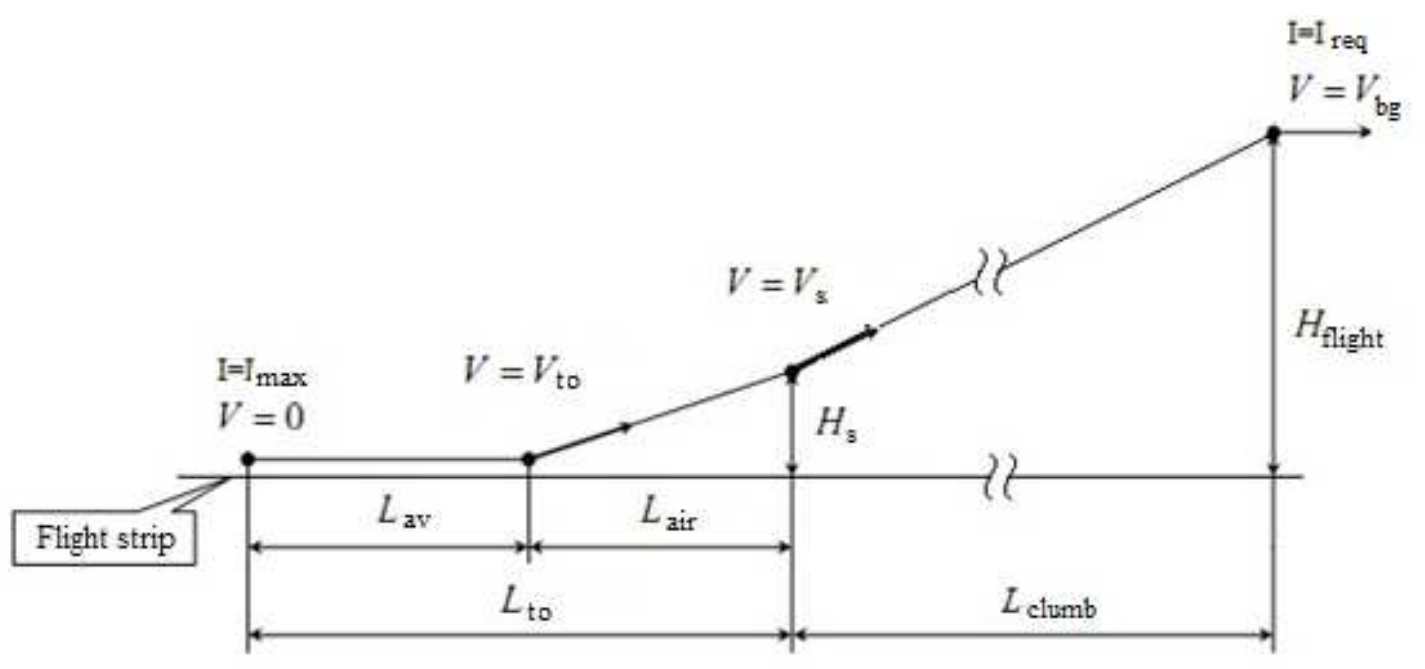

Fig. 3. Characteristic areas and flight modes

As a result of calculations using formulas (1-4) and the initial data, the dependence $N_{r e q}=f(V)$ is constructed in the expected speed range with some overlap. An example is shown in Figure 4

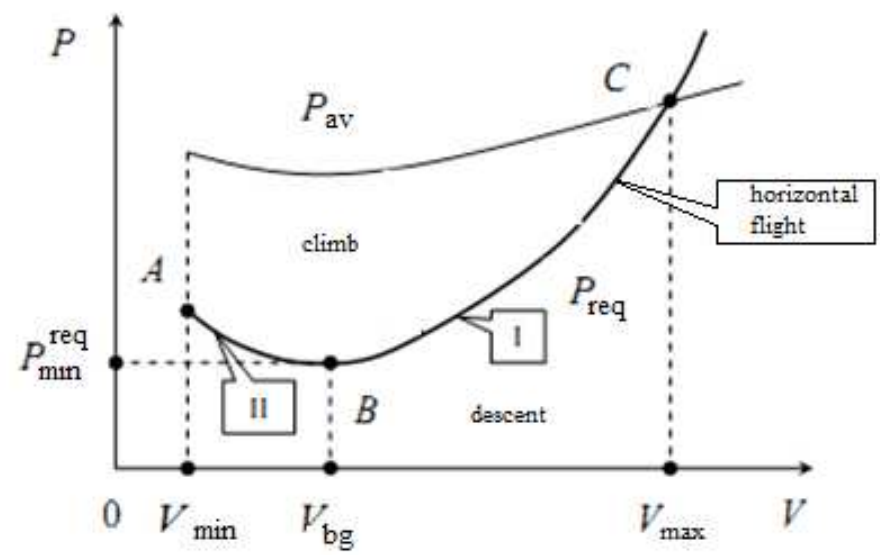

Fig. 4 Required and available thrusts

The $A B C$ curve corresponds to the established level flight. Point $A$ corresponds to the minimum speed $V_{\min }$. Point $B$ corresponds to the best glide speed of $V_{b g}$ and the minimum required thrust $P_{\min }^{r e q}$. The point $C$ curve crossing of the required and available thrusts corresponds to the maximum speed $V_{\max }$ [1]

The area lying above the curve $A B C$ at each point of which the realizable thrust $P$ exceeds the required thrust $P_{r e q}$ is the area of established climb speed. The area lying below the curve $A B C$ at each point of which the realizable thrust $P$ is less than the required thrust $P_{r e q}$ is the area of established decline.
Calculation of maximum speed and climb rate.

To determine the values of the maximum flight speed and climb rate, the dependence of the available propeller power on speed [3] is spotted on the graph shown in Fig. 2:

$$
N_{a v}=N_{m} \cdot \eta_{\text {prop }}=\frac{P_{p r o p} \cdot V}{270}
$$

where $\eta_{\text {prop }}-$ total efficiency of the propeller [9] and gearbox;

$$
P_{\text {prop }} \text { - propeller thrust. }
$$

The right point of curve crossing $N_{a v}(V)$ and $N_{r e q}(V)$ determines the maximum speed of level flight.

Climb rate is calculated by the formula:

$$
V_{y}=\frac{75\left(N_{a v}-N_{r e q}\right)}{G} .
$$

In this case, the dependence $V_{y}(V)$ is constructed in the figure and the most advantageous climb rate is determined, at which the maximum value $V_{y}$ is reached.

\section{Determining takeoff and landing parameters.}

The takeoff is the stage of the aircraft's movement from the takeoff run to safe speed $V_{2} \geq 1.2 V_{s}$ and the height $\mathrm{H}_{2}$ simulated obstacle according to the accepted norms is $10.7 \mathrm{~m}$. The basic parameter in determining the take-off and landing characteristics of the aircraft is the value of the minimum possible stall speed in the landing position. 


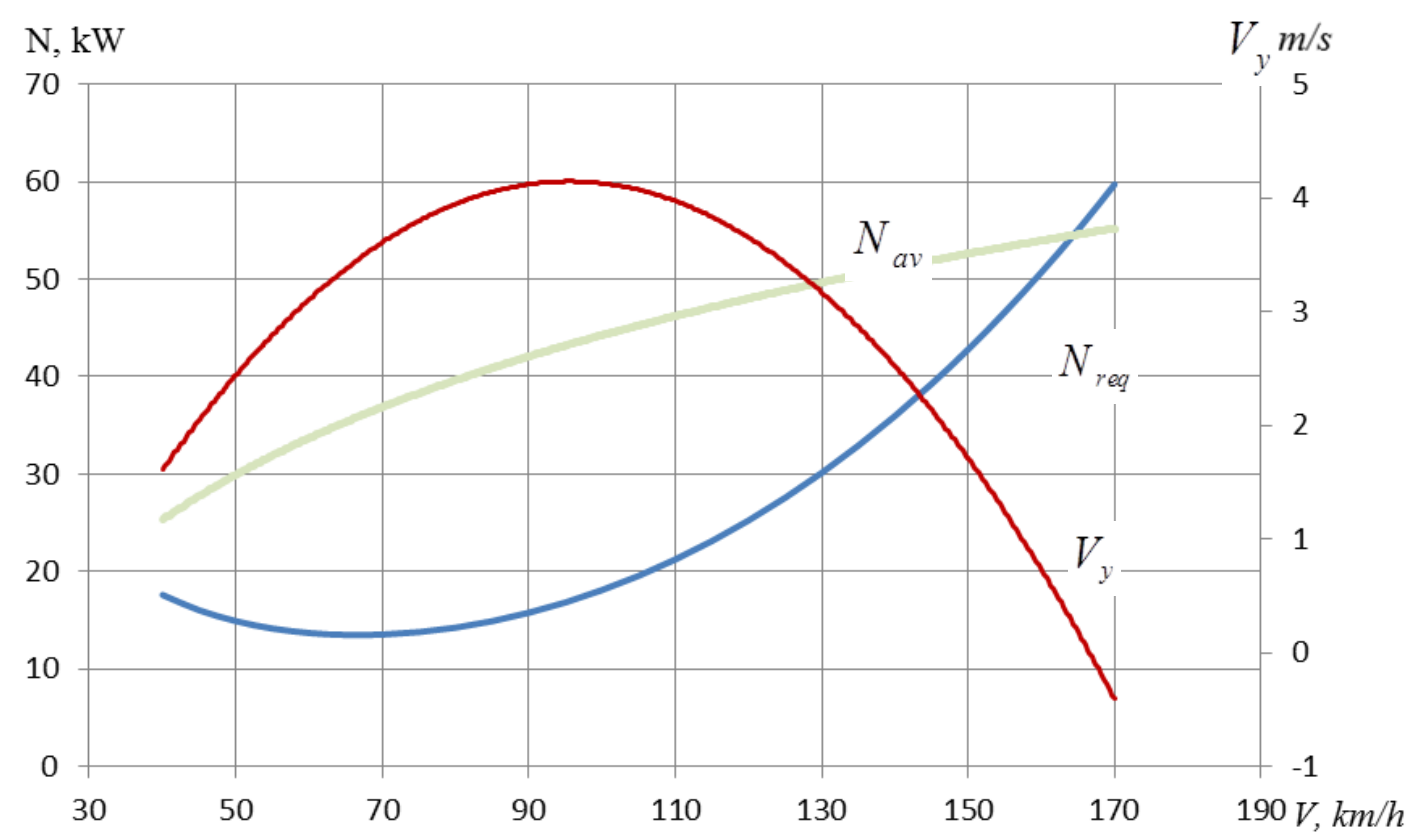

Fig. 5 Aeroprakt A-22 required and available thrusts

On a takeoff mode, the lift-off speed, the take-off run and the total take-off distance are calculated, including the take-off area up to the height $\mathrm{H}_{2}$.

According to general technical requirements, the lift-off speed should be not less than $1.1 V_{s}$.

The run length is:

$$
L_{r} \approx 0.004 \frac{V_{t o}^{2}}{\left(\frac{P_{a v r}}{G}-f_{f r}\right)}
$$

where $P_{a v r}$ - average thrust on take-off run;

$f_{f r}$ - friction coefficient of the chassis on the runway.

After lift-off, the aircraft is accelerated to safe speed $V_{2}$ which must exceed the takeoff stall speed by at least $20 \%$ followed by climb to safe height $H_{2}=10.7 \mathrm{~m}$.

The air way length of the flight distance:

$$
L_{\text {air }} \approx \frac{H_{2}+\frac{V_{2}^{2}-V_{t o}^{2}}{254}}{\left(\frac{P_{a i r}}{G}-\frac{1}{K_{a i r}}\right)} .
$$

The obtained values are used to calculate the engine operating time with different power that in turn allows you to calculate the energy consumption, flight range and energy intensity.
In carrying out this work, an electric drive was selected for the Aeroprakt A-22 airplane based on the EMRAX 228 axial flux synchronous permanent magnet motor [10] and the power storage device based on a lithium-iron-phosphate battery with a total capacity of $28.8 \mathrm{kWh}[11,12]$.

TABLE I. POWER UNITS WEIGHT

\begin{tabular}{|l|c|}
\hline Unit & Weight, kg \\
\hline Engine & 58.3 \\
\hline Rectifier-regulator & 0.3 \\
\hline Vacuum pump & 0.8 \\
\hline Overload clutch & 1.7 \\
\hline Subsidiary generator & 3.0 \\
\hline Cooling cover & 0.8 \\
\hline Steel pipelines of fuel system & 0.25 \\
\hline Stainless steel exhaust system & 4.0 \\
\hline Cylindrical air filter & 0.38 \\
\hline Single-section radiator with cover & 1.28 \\
\hline Expansion tank & 0.16 \\
\hline Input Receiver with air heated & 1.1 \\
\hline Fuel filter & 0.01 \\
\hline Filling Syringe & 0.15 \\
\hline Fuel tanks & 18 \\
\hline Total & 90.23 \\
\hline
\end{tabular}




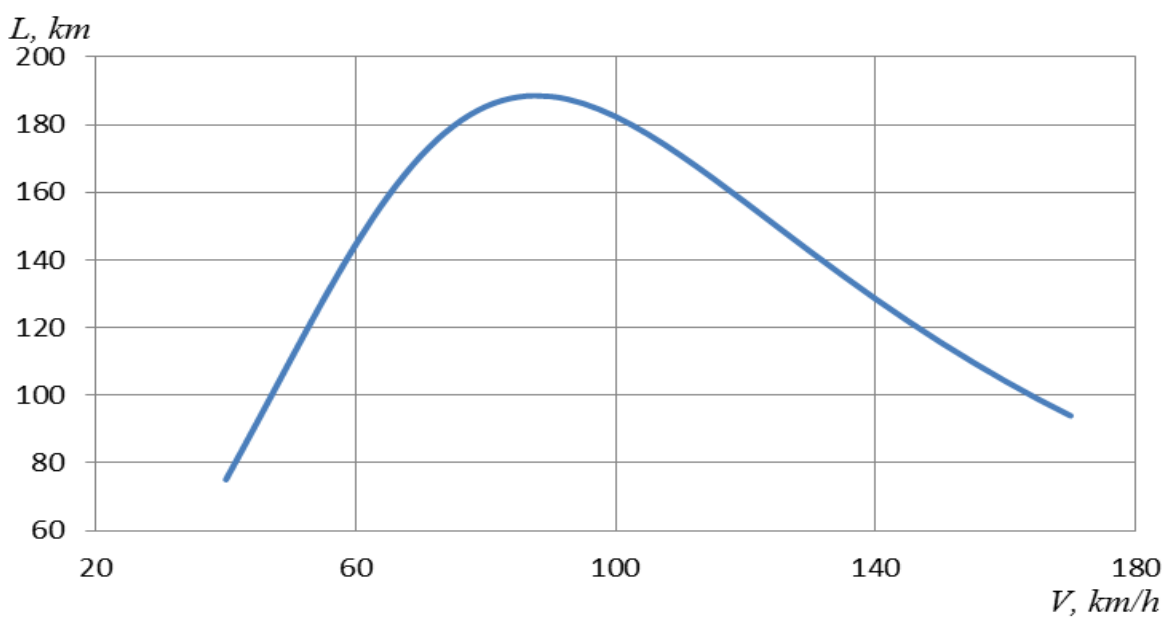

Fig. 6 Dependence of flight range on speed

The power unit weight is composed of the engine's masses with the gearbox, propeller and auxiliary units. Table 1 shows weights of assemblies and units, which can be discarded in case of the electric motor instead of the internal combustion engine. [13]

Total mass of the power plant was $168 \mathrm{~kg}$, which corresponds to the mass of the engine Rotax-912 including the fuel system. Figure 5 shows a diagram of the available and required thrusts for the selected aircraft.

The graph shows that the maximum speed for horizontal flight is $V_{\max }=165 \mathrm{~km} / \mathrm{h}$. The most advantageous climb speed, which corresponds to the minimum energy intensity and maximum climb rate, is $V=95 \mathrm{~km} / \mathrm{h}$.

To estimate the range of flight with the selected power unit, the energy consumption for take-off and horizontal flight at an altitude of $1000 \mathrm{~m}$ was calculated.

The total running time of the engine on takeoff, which is necessary for take-off and ascent [4], was $266 \mathrm{~s}$, which corresponds to an energy consumption of $4.1 \mathrm{kWh}$

As can be seen from Figure 6, the flight range is directly dependent on the selected speed. The maximum value can be achieved with the maximum aerodynamic quality and corresponds to $N_{a v}=12.6 \mathrm{~kW}$. With this mode, the maximum range is $193 \mathrm{~km}$.

\section{CONCLUSION}

The analysis of the obtained results showed that for twoseater ultra-light aircraft Aeroprakt A-22, maximum long range aircraft decreased slightly more than 2 times and is about $200 \mathrm{~km}$ that allows us to use the aircraft as training, for aerial photography and other purposes at working on short run. These parameters can be improved by using photo cells, the battery charge will be charged by solar energy both during the flight and parked aircraft in open areas.

Such remotorization to a greater extent is applied for gliders with excellent aerodynamic quality and do not require high engine power to maintain level flight. This glider is able to take off independently without using a winch or tow-plane.

\section{REFERENCES}

[1] Stefan Stückl, "Methods for the Design and Evaluation of Future Aircraft Concepts Utilizing Electric Propulsion Systems" Dissertation; Technical University of Munich 2016.

[2] V.V.Biryukov Energy aspects for transport system operation: monograph, Novosibirsk: NSTU, 2014.

[3] Jeremy Fehrenbacher, David L. Stanley, Mary E. Johnson, Jeffrey Honchell "Electric Motor \& Power Source Selection for Small Aircraft Propulsion". College of Technology Directed Projects, pp. 33, 2011.

[4] V.V. Biryukov, Electric traction drive: teaching manual, Novosibirsk: NSTU, 2013, 314 p.

[5] Wenping Cao; Barrie C. Mecrow; Glynn J. Atkinson; John W. Bennett; David J. Atkinson "Overview of Electric Motor Technologies Used for More Electric Aircraft (MEA)" IEEE Transactions on Industrial Electronics, Vol. 59, Issue 9, 2012.

[6] V.L, Balakin, Yu.N.Lazarev, Airplane flight dynamics. Calculation of trajectories and flight characteristics SGAU, 2011

[7] V.E. Rosenfeld, I.P. Isaev, N.N. Sidorov, M.I. Ozerov Electric traction theory: A textbook for high schools. Transp, M .: Transport, 1995.

[8] A manual for designers of flying machines on self-constructing - RDK SLA SibNIA named after. S.A. Chaplygin, 1989

[9] S.D.Salenko, A.D. Obukhovsk, Dynamics of flight, part 2: aircraft stability and controllability, Novosibirsk State Technical University, 2015.

[10] AEROPRAKT-22LS Flight Manual.

[11] EMRAX User's Manual for Advanced Axial Flux Synchronous Motors and Generators.

[12] Muntwyler Urs, Andrea Vezzini "Electric flight - history - state of the art and first applications" KINTEX, Korea, 2015

[13] Ranjan Vepa "Modeling and Dynamics of HTS Motors for Aircraft Electric Propulsion" School of Engineering and Material Science, Queen Mary, University of London 2018 